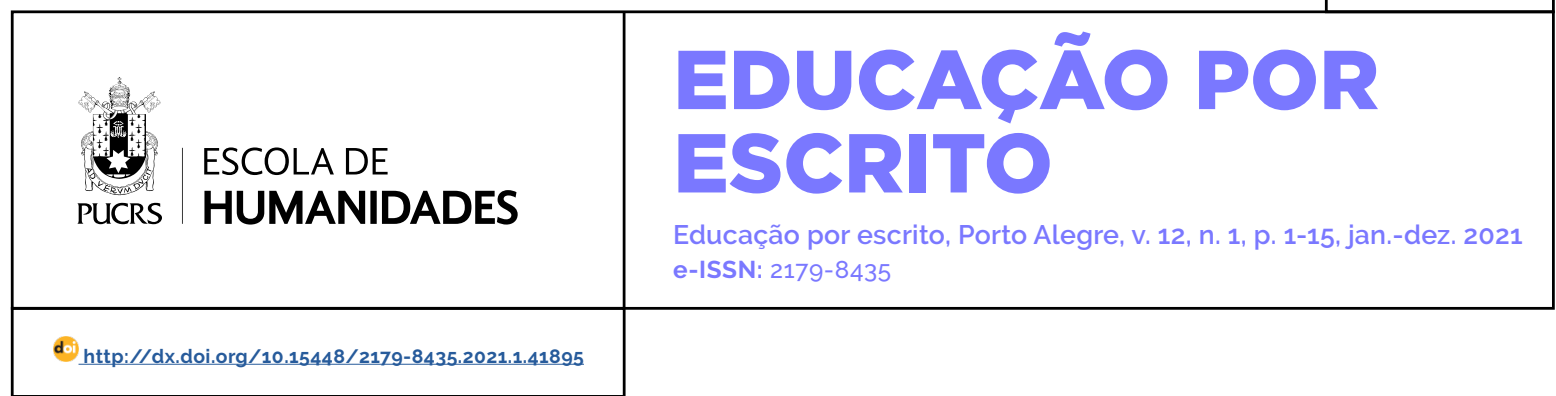

SEÇÃO: A FORMAÇÃO DE PROFESSORES E A EDUCAÇÃO INCLUSIVA: AVANÇOS, DESAFIOS E PERSPECTIVAS

\title{
A visão dos professores do Atendimento Educacional Especializado acerca do trabalho desenvolvido e formação ofertada
}

The view of the Specialized Educational Service teachers about the work developed and the training offered

\section{Elisangela Leal de \\ Oliveira Mercado ${ }^{1}$}

orcid.org/0000-0003-2815-4813

elisangela.mercado@cedu.ufal.br

\section{Neiza de Lourdes \\ Frederico Fumes ${ }^{1}$}

orcid.org/0000-0002-1913-4784

neiza.fumes@iefe.ufal.br

Recebido em: 30/09/2021. Aprovado em: 12/11/2021. Publicado em: 22/12/2021.
Resumo: Este artigo aborda como professores que atuam no Atendimento Educacional Especializado (AEE) compreendem o trabalho realizado junto aos estudantes público-alvo da Educação Especial (PAEE) e a relação desse com a formação ofertada pela Secretaria de Educação. Tem o objetivo de conhecer a visão dos professores do AEE acerca do trabalho desenvolvido e formação ofertada. Baseado nos estudos de Mendes e Malheiro (2012), Vaz (2012) e Baptista (2013), constitutivos no desvelar da atuação e formação dos professores da Educação Especial, assume no âmbito da pesquisa qualitativa a técnica do grupo focal e a aplicação de questionário sobre o perfil de formação profissional. Participaram do grupo focal doze professores de escolas públicas estadual e municipais de Alagoas. Os resultados analisados indicam que aspectos relacionados à constituição do processo identitário e atuação profissional encontra-se baseados na concepção clinica-terapêutica de deficiência e prática profissional centrada, basicamente, na aplicação de recursos pedagógicos e de acessibilidade. Apontam a necessidade de discussão da atuação e formação do professor da Educação Especial, à luz da dimensão sociopolítico-pedagógica do fazer docente.

Palavras-chave: Educação Especial. Atendimento Educacional Especializado. Professores.

Abstract: This article discusses how teachers who were engaged in Specialized Educational Service (AEE) understand the work carried out with students target audience of Special Education (PAEE) and their relationship with the training offered by the Department of Education. Its objective is to get to know the vision of the AEE professors about the work developed and the training carried out. Based on the studies by Mendes and Malheiro (2012), Vaz (2012) and Baptista (2013), constitutive in the unveiling of the performance and training of Special Education teachers, the focus group technique and the application of a questionnaire are used in qualitative research. Twelve teachers from state and municipal public schools in Alagoas participated in the focus group. The results show that aspects related to the constitution of the identity process and professional performance are based on the clinical-therapeutic conception of disability and professional practice centered, basically, on the application of pedagogical resources and accessibility. They point to the need to discuss the formation and training of teaching Special Education teachers, in light of the sociopolitical-pedagogical dimension of.

Keywords: Special Education. Specialized Educational Service. Teachers.

\section{Introdução}

O cenário de democratização da educação pública, configurado no início dos anos 1990, mostra-se bastante promissor na garantia do di- 
reito a educação às pessoas com deficiência. A Declaração Mundial sobre Educação para Todos (UNESCO, 1990) e a Declaração de Salamanca (UNESCO, 1994) defendem a ideia de escola para todos, ampliando a discussão para criação de políticas públicas voltadas à inclusão de crianças, jovens e adultos com deficiências em escolas regulares.

A Lei de Diretrizes e Bases da Educação Nacional (LDB) - Lei n 9.394/1996 determina que os sistemas de ensino devem assegurar aos estudantes com deficiências, transtornos global do desenvolvimento e altas habilidades/superdotação, considerados público-alvo da Educação Especial (PAEE), "currículos, métodos, recursos educativos e organização especifica, bem como professores com especialização adequada para atendimento especializado" (BRASIL, 1996, p. 45), tendo em vista a incumbência dos professores de "zelar pela aprendizagem dos seus alunos" (BRASIL, 1996, p. 10). A compreensão de inclusão escolar passa por uma concepção de educação que legitima a escola como aquela que acolhe os diversos e que precisa se organizar para adequar suas ações as diferenças.

Na primeira década de 2000, o movimento em prol da construção de sistemas educacionais inclusivos avança na implantação de políticas educacionais voltadas ao fortalecimento do Atendimento Educacional Especializado (AEE), a criação de Salas de Recursos Multifuncionais (SRM), a exigência de acessibilidade dos prédios escolares, a expansão do acesso e permanência das pessoas com deficiência na educação básica e superior, o acesso ao Benefício de Prestação Continuada (BPC Escola) e a implementação dos programas de formação de professores para Educação Inclusiva.

A política de inclusão dos estudantes PAEE rompe com um modelo de educação especial de via paralela ao sistema educacional e prioriza um modelo de escolarização via única com a matricula desses estudantes em um único sistema regular de ensino, na sala de aula comum. De acordo com Mendes e Malheiro (2012) este movimento tem início com a inclusão do termo
AEE na Constituição Federal de 1988. Ao longo das três décadas de oferta do AEE, a compreensão deste tipo de atendimento sofreu algumas mudanças: em substituição a Educação Especial, demarcando um novo modelo de escolarização para esses estudantes; como sinônimo da Educação Especial, visto como uma modalidade de educação escolar ofertada preferencialmente na rede regular de ensino; como um serviço da Educação Especial, de apoio aos estudantes PAEE escolarizados na sala de aula comum, com lócus prioritário em SRM. Considerando que estudantes PAEE devem ter assegurado a oferta do AEE pelos sistemas de ensino, de forma complementar ou suplementar ao currículo escolar realizado no contraturno do período que ele frequenta a sala de aula comum, a formação dos professores de Educação Especial busca prepará-lo para atuar com a diversidade desses estudantes em contexto inclusivo.

No contexto de reordenamento dos sistemas de ensino e construção de um sistema educacional inclusivo a Educação Especial, antes segregadora e substitutiva com a existência de classes e escolas especiais, passa a ser considerada de modo transversal da educação infantil à superior. Demarca-se assim um novo paradigma educacional, no qual o professor de Educação Especial sai do contexto de atendimento/ensino especializado e passa a atuar em escolas regulares no contato com professores de sala de aula comum, resultando em desafios a atuação e formação dos professores de Educação Especial e nos leva a pensar: a formação o qualifica professores do AEE para uma atuação que atenda às necessidades dos estudantes? Como se percebem diante do trabalho desenvolvido no contexto educacional inclusivo? Tais inquietações nos provocou a ouvi-los, em busca de conhecer a visão que têm sobre o trabalho desenvolvido e a relação desse trabalho com as formações ofertadas pelas Secretarias de Educação.

Este artigo, ao abordar como professores que atuam no AEE compreendem o a formação docente e o trabalho realizado, tem o intuito de conhecer a visão desses profissionais acerca do 
trabalho desenvolvido e formação ofertada pelas Secretarias. Com um olhar reflexivo teceremos uma compreensão da visão desses profissionais com os estudos de Mendes e Malheiro (2012), Vaz (2012), Baptista (2013) e outros, no desvelar da visão docente acerca da atuação e formação dos professores da Educação Especial.

A abordagem metodológica consistiu em pesquisa qualitativa de natureza exploratória, a qual buscou compreender a relação significado e intencionalidade como aspectos inerentes a constituição do ser social, procurando entender e interpretar o fenômeno a partir da perspectiva dos participantes. Utilizou-se o grupo focal como técnica de pesquisa, por propiciar um rico momento de discussão de questões e experiências cotidianas, a partir da adesão voluntária de participantes que tem uma vivência com o tema (GATTI, 2005). Participaram do grupo focal doze professores efetivos que atuam no AEE em escolas públicas estadual e municipais de Alagoas. Antes da a realização do grupo focal, foi aplicado um questionário com esses professores para identificar o perfil da formação profissional de cada um.

\section{Professores que atuam no AEE}

Para garantir as condições de permanência, participação e aprendizagem dos estudantes PAEE no sistema regular de ensino, o artigo $3^{\circ}$ do Decreto $n^{\circ}$ 7.611/2011 determina que o AEE deve:

I - prover condições de acesso, participação e aprendizagem no ensino regular e garantir serviços de apoio especializados de acordo com as necessidades individuais dos estudantes;

II - garantir a transversalidade das ações da educação especial no ensino regular;

III - fomentar o desenvolvimento de recursos didáticos e pedagógicos que eliminem as barreiras no processo de ensino e aprendizagem;

IV - assegurar condições para a continuidade de estudos nos demais niveis, etapas e modalidades de ensino (BRASIL, 2011, p. 2).

O AEE não deve ser confundido com reforço escolar, ao invés disso é concebido como um con- junto de atividades, recursos de acessibilidade e pedagógicos com procedimentos específicos, voltado às necessidades dos estudantes PAEE. Dessa forma, cabe ao professor especializado garantir o aprendizado em Braille, Libras, Comunicação Aumentativa Alternativa (CAA), Tecnologia Assistiva (TA) e um curriculo flexivel, permitindo oportunidades iguais de aprender, considerando suas especificidades e necessidades. Além de dispor de atenção especial, escuta qualificada e conhecimentos específicos para propor estratégias e metodologias diferenciadas, que auxiliem no processo de aprendizagem.

A opção pela nomeação dos professores participantes desta pesquisa em professores que atuam no AEE ao invés de professores de Educação Especial deu-se pela diversidade na formação profissional e pela ausência de uma formação específica nesta modalidade de ensino. Com base no questionário aplicado, o perfil de formação inicial dos doze professores participantes do grupo focal demonstra que a maioria tem licenciatura em Pedagogia (Gráfico 1) e especialização em Psicopedagogia (Gráfico 2). Alguns professores marcaram mais de uma opção, pois declararam terem feito mais de uma graduação e especialização.

Gráfico 1 - Formação Inicial

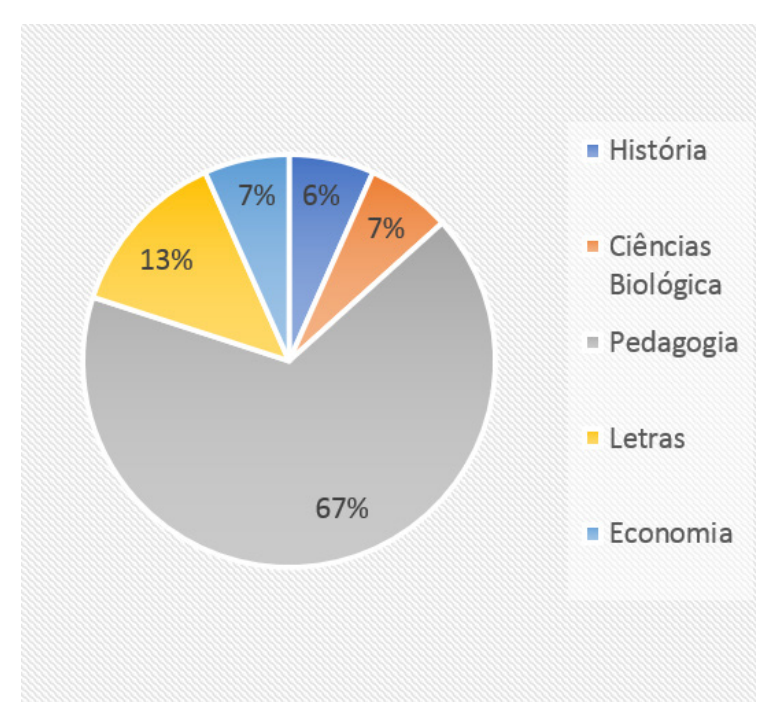

Fonte: Elaborado pelas autoras (2016). 
Gráfico 2 - Formação Continuada

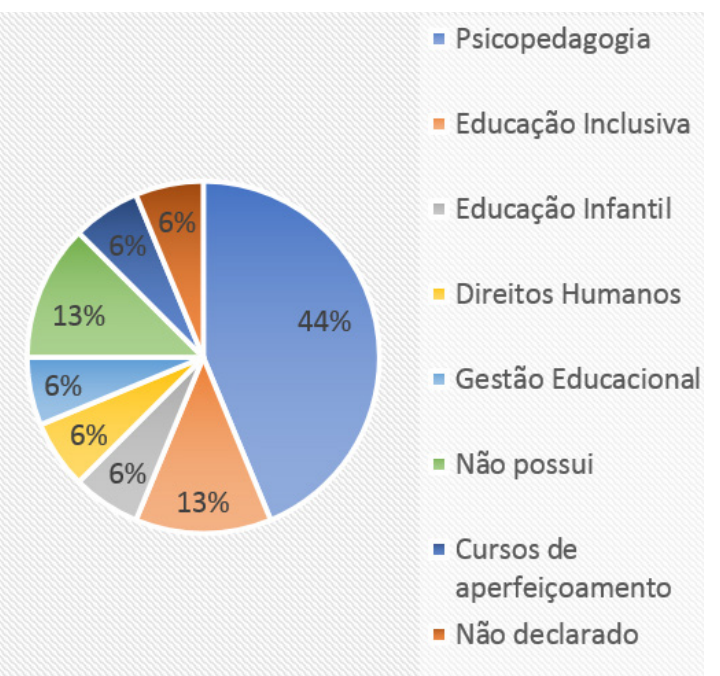

Fonte: Elaborado pelas autoras (2016).

Os gráficos 1 e 2 retratam que o percurso de formação inicial dos professores é diversificado, variando desde cursos de licenciatura em Pedagogia, Letras, Ciências Biológicas e História, até curso de bacharelado em Economia como primeira graduação e Pedagogia como segunda licenciatura em instituições de natureza pública ou privada. Este dado se assemelha ao divulgado no Relatório da Situação Mundial das Crianças com Deficiência (UNICEF, 2013, p. 32), ao identificar que "os professores são elemento fundamental no ambiente de aprendizagem da criança". Entretanto, muitos dos professores entrevistados não tinham formação para ensinar crianças com deficiência. Tal situação alerta para a importância de políticas públicas que pensem na formação docente, entendendo que o professor da sala de aula comum precisa ter conhecimentos relacionados ao processo de ensino e aprendizagem dos estudantes PAEE, apoiado e sob orientação do professor de Educação Especial; e o professor de Educação Especial deve ter uma formação para além da identificação e categorização da condição de deficiência, abordando o currículo escolar e a natureza do trabalho pedagógico em contexto inclusivo (BITENCOURT; ARAÚJO, 2014).

No caso da formação continuada identificamos que entre os declarados, a maioria dos professores tem curso de especialização (Psicopedagogia,
Educação Inclusiva, Educação Infantil, Direitos Humanos e Gestão Educacional) e, apenas, três professores não têm especialização, a saber: um com aperfeiçoamento e dois com graduação. $O$ curso de aperfeiçoamento mencionado faz referência ao ofertado pelo Ministério da Educação (MEC) em parceria com a Secretaria de Educação, como requisito para atuar na SRM.

Em meados dos anos 2000, o MEC, como parte da política de fortalecimento da educação inclusiva, pactuou com as Secretarias de Educação a oferta de cursos de aperfeiçoamento/especialização em AEE, TA ou Educação Inclusiva. A Politica Nacional de Educação Especial na Perspectiva da Educação Inclusiva (PNEE-El/2008) estabelece que, "para atuar na educação especial, o professor deve ter como base da sua formação, inicial e continuada, conhecimentos gerais para o exercício da docência e conhecimentos específicos da área" (BRASIL, 2008, p. 13). Determina que, no exercicio e na experiência de trabalho com estudantes PAEE, o professor deve conhecer as especificidades de cada condição de deficiências e ser preparado para orientar os demais profissionais da escola e familiares sobre CAA, TA, redimensionamento da organização escolar e curricular e construção de um Projeto Político Pedagógico (PPP) equitativo e inclusivo, voltado à garantida da educação como direito social. A formação deve proporcionar, de forma reflexiva e dialógica, a melhoria da prática pedagógica rompendo a barreira do isolamento, do capacitismo e das atividades didáticas ou de um currículo limitado e excludente. Considerando que o foco do programa implantação de SRM (BRASIL, 2007) é formar o professor para atuar no AEE, as agências formadoras utilizam a estratégia de formação em serviço para instrumentalizar os professores no atendimento a todos os estudantes público-alvo dessa modalidade de ensino.

Os sujeitos da pesquisa, questionados acerca do tempo que concluiram seus estudos e se a Secretaria oferta formação continuada, declararam que concluiram a formação inicial e/ou continuada há mais de 5 (cinco) anos. A exceção são dois professores da rede municipal que ainda 
cursavam Pedagogia, como segunda licenciatura. Para manter-se atualizados, são ofertados momentos de formação em serviço para todos os profissionais da educação. Os professores relataram a participação de encontros de formação continuada, em geral, oferecidos pela rede de ensino via Secretarias de Educação. Esses encontros na rede municipal de ensino ocorriam quinzenalmente, com duração anual (BARROS, 2010) e na rede estadual de ensino, ocorrem esporadicamente ou a depender do calendário e interesse de cada Coordenadoria Regional de Ensino.

De acordo com Miranda (2015, p. 13) a formação de professores para ambientes escolares inclusivos tem sido tema de vários discussão e debate no meio educacional, em especial, quando se discute a inclusão escolar e, alerta que "a formação docente ainda não qualifica uma atuação eficiente e satisfação pessoal do próprio professor", tendo em vista que o MEC tem adotado diversas medidas para promover a formação de professores que atuam em sala de aula comum e no AEE.

Assim, na busca de conhecer a visão dos professores que atuam no AEE em Alagoas acerca do trabalho desenvolvido e formação ofertada pelas Secretarias, analisaremos trechos da fala destes, identificando os desafios e as vivências constitutivas do dia a dia da prática profissional.

\section{A visão dos professores sobre sua atuação profissional}

Ao serem questionados sobre o papel desempenhado na escola regular em vias do processo de inclusão escolar, os professores ${ }^{2}$ relataram os desafios vividos diante da sobrecarga de atividades e do novo perfil de alunado da Educação Especial. $^{3}$

[...] você falou com quem trabalha na prática... aconteceu um caso de um deficiente intelectual que foi a tarde inteira... só dando atenção à essa menina... só... ela teve um surto lá... (Professor J, informação verbal).
[...] e como você deve agir? Fala... diante de uma coisa dessa... que situação difícil... (Professor C, informação verbal).

[...] chamo a familia... foi a tarde inteira ... teve caso de vir a SAMU... quer dizer até... (Professor $J$, informação verbal).

[...] até prestação de primeiros socorros... faz parte, né? (Professor C, informação verbal).

[...] porque é assim, né... eu costumo até brincar, né... porque a gente é polivalente, né... a gente tá ali, né... porque o próprio atendimento do AEE... ele diz quais são os alunos que a gente tem que atender, né... então nós estamos ali como polivalentes temos que entender um pouco de tudo... por exemplo a minha especialização ela foi em deficiência intelectual... então eu imaginei que, né... eu iria trabalhar só com esse público, só que não... e as vezes eu me coloco um pouco na situação do professor de sala de aula (Professor A, informação verbal).

[...] mas ai também eles estão pressupondo que enquanto professor é igual que ela colocou polivalente [GESTICULA OS DEDOS COMO SE ABRISSE E FECHASSE ASPASI mesmo? (Professor C, informação verbal).

As falas apontam que o modelo de atendimento proposto reforça o conflito entre o paradigma da atuação profissional do professor de Educação Especial e do professor de AEE. A disparidade entre essas atribuições tem despertado críticas, para Mendes e Malheiro (2012) a Resolução $n^{\circ}$ 2/2001 traz uma tímida inovação ao apresentar uma proposta que permite que esse professor atue no apoio ao professor da sala de aula comum e não apenas na provisão de serviços complementares e, em alguns casos, substitutivos. Para Baptista (2013), há um ensaio para que o professor de Educação Especial ultrapasse o foco nas deficiências e passe a atuar pedagogicamente com os diferentes campos na escola (na assessoria e formação dos professores da sala de aula regular, no acompanhamento às famílias dos assuntos que envolvem o aprendizado dos estudantes e no envolvimento com a proposta pedagógica e gestão da escola), em prol do processo educacional.

A radicalização da política de inclusão escolar, que introduziu a SRM como lócus prioritário para oferta do AEE, resultou na aprovação da Reso-

\footnotetext{
2 Os professores serão tratados de forma anônima, indicadas com letras alfabéticas para preservar suas identidades.

Os depoimentos apresentados no artigo são de professores participantes do Grupo Focal e foram concedidos às pesquisadoras em evento do Observatório Estadual da Educação Especial de Alagoas, na cidade Maceió, Alagoas, Brasil, no dia 10 de março de 2016.
} 
lução CNE/CEB n 4/2009. No entanto, essa resolução tem causado inquietações ao exigir do professor especializado conhecimentos amplos e diversificados, considerando que este profissional tem a responsabilidade de responder, em uma ou duas horas de atendimento no contraturno da sala de aula comum, às necessidades diferenciadas das mais variadas crianças que compõem o PAEE.

Na sala de recursos o professor especializado terá a impossivel tarefa de dar conta do AEE dos mais variados tipos de alunos, o que nos faz pensar se o termo 'multifuncional' adotado pela política não seria um adjetivo atribuído mais ao professor do que ao tipo de classe! (MENDES; MALHEIRO, 2012, p. 363).

A análise das autoras sobre a multifuncionalidade do professor de AEE pode ser identificada na fala de um dos professores, participantes do grupo focal, ao se reconhecer como "polivalente" precisando "entender de tudo um pouco" (Professor A, informação verbal), já que sua formação acadêmica foi no âmbito da deficiência intelectual. O professor de Educação Especial acaba, muitas vezes, angustiado seja por causa da restrição no modelo de formação ofertado ou imposto. Somado a isto temos também o conjunto de atribuições que deve desempenhar.

Vaz (2012) aponta o caráter reducionista da atuação profissional imposta com a Resolução CNE/CEB n 4/2009. A concepção de professor, com a priorização do AEE e da SRM, é reconvertida a função técnico-gestor do serviço de apoio à escolarização de estudantes incluidos. As novas atribuições como intermediador dos serviços e recursos pedagógicos e de acessibilidade desvelam a perda do cerne da ação docente e a real importância que esse profissional passa a ocupar na PNEE-El/2008. O professor J relata que o contato com a familia gira em torno da condição de deficiências e das alterações comportamentais.

Considerando a dificuldade do professor de Educação Especial ultrapassar a visão de professor especializado em deficiências, a fala dos professores $A$ e $V$ reforça que a atuação profissional deve ser orientada pelo tipo de deficiência.

\begin{abstract}
[...] quando eu fiquei o primeiro semestre na sala regular e agora eu fui contemplada com a sala do AEE é ótimo em planejar eu posso trabalhar com o menino... com autista... com o DI e com... (Professor V, informação verbal).

[...] cada caso é um caso, entendeu! as realidades são bem diversificadas... eu posso ter um aluno que tenha um comprometimento... um aluno que tenha... por exemplo seja autista... mas não apresente o mesmo comportamento do que o outro que tá naquele momento lá de atendimento comigo... então todo trabalho tem que ser voltado realmente para uma adaptação de recursos para aquele aluno... (Professor $A$, informação verbal).
\end{abstract}

Amparados pelo paradigma de ênfase na dimensão técnica da atuação profissional esses professores demonstram uma preocupação restrita à condição de deficiência de cada estudante. A oferta do AEE restrita à SRM reforça a concepção de que o atendimento ao estudante PAEE necessita de espaço e de planejamento específicos. Com isso, o acompanhamento e a aplicação dos recursos pedagógicos e de acessibilidade configuram-se como uma atribuição específica de tais professores, complementada pela atribuição de atender cada estudante na sua especificidade. Este é um posicionamento que se mostra em consonância com as determinações previstas na Resolução CNE/CEB n 4/2009, além de reforçar a sobreposição do olhar clínico sobre a subjetividade do sujeito.

O professor F. defende que o professor de Educação Especial para atender as especificidades do estudante precisa, antes, conhecer o diagnóstico clínico e então escolher o recurso mais adequado para mudar seu comportamento.

[...] aí... ou seja tem os niveis de autismo nem todos eles vão se incomodar... o J pra mim, ele é esse menino, é mais do que normal, ele é muito, muito inteligente, ele é tudo de bom... mas ele tem autismo, sim eu já percebi essas características muitos... mas é diagnosticado pelo médico e ele pense mas há quem diga esse menino é não tem um grau... mas ele tem um grau de autismo. graças à Deus é bem moderado, mas ele tem e a gente percebe... mas ai eu perguntei pra ele, morrendo de medo se não ele começava a quebrar a sala toda, ele não gosta né? Quando eles não gostam, os brinquedinhos se foram, ele saiu, que trava 
exposto... ele foi pegando, hoje ele tá bem mais calmo (Professor F, informação verbal).

É uma fala que chama a atenção por estar baseada em uma visão de piedade, pieguismo, de sujeito que precisa ser superprotegido. Falta clareza do trabalho a ser realizado ao descrever a natureza da ação docente baseada na esfera da "caridade", a qual necessitar de um laudo médico para se ter certeza do tipo de atendimento a ser desenvolvido.

Além da falta de clareza e objetividade do papel a ser desempenhado, o discurso acerca do estudante com autismo aponta que o desafio da atuação profissional está relacionado ao problema identificado: "ele tem um grau de autismo graças à Deus é bem moderado" ou "ele é muito, muito inteligente, ele é tudo de bom... mas ele tem autismo" ou "mas aí eu perguntei pra ele, morrendo de medo" (Professor F, informação verbal). Tais falas que apontam que o processo de inclusão escolar emerge concepções de deficiências que inviabilizam o processo de aprendizagem, pois partem do principio de que a condição de deficiências norteia todo processo de desenvolvimento e aprendizagem.

O professor de Educação Especial deve, antes de tudo, abandonar mitos e crenças acerca das pessoas com deficiências e atuar de forma qualificada, não se limitando a etiologia e diagnóstico dos tipos de deficiências atendidos na SRM. Sua atuação profissional não se restringe a um espaço físico, muito menos está centralizada em um sujeito a ser corrigido. A fala do professor $F$ aponta que a atuação do professor de Educação Especial que, muitas vezes, encontra-se reduzida à preocupação de ensinar o uso de recursos específicos, transformando a SRM em espaço de atendimento clínico e espaço exclusivo de atuação terapêutica, eliminando o caráter educacional e formativo da atuação docente.

O professor de Educação Especial não pode ter sua prática profissional restrita de um modelo de clínico de deficiência, ainda que o trabalho desenvolvido se sobreponha ao domínio de técnicas, de códigos, de manuseio e treino de recursos. Pletsch (2009) enfatiza que o professor de Educação Especial deve valorizar a diversidade como elemento importante no processo ensino e aprendizagem, além de construir estratégias de ensino, adaptar atividades e conteúdo, não só em relação aos estudantes PAEE atendidos, mas na vertente de melhoria da prática pedagógica como um todo.

Identificamos no trabalho desenvolvido pelos professores F, A, J e C a ausência da dimensão política-pedagógica do Ser professor. A prática docente é um posicionamento político assumido por um profissional envolvido na garantia do direito à educação de crianças, jovens e adultos com deficiências, transtornos globais de desenvolvimento e altas habilidades/superdotação. Ao sair dos muros da escola especial e adentrar a escola regular, o professor de Educação Especial passa a ter o fazer pedagógico norteado por um modelo de escola voltado à formação de cidadãos conscientes, responsáveis e críticos, que atuarão na sociedade, muitas vezes, transformando-o.

\begin{abstract}
A luta dos professores em defesa de seus direitos e de sua dignidade deve ser entendida como um momento importante de sua prática docente, enquanto prática ética. Não é algo que vem de fora da atividade docente, mas algo que dela faz parte. O combate em favor da dignidade da prática docente é tão parte dela mesma quanto dela faz parte o respeito que o professor deve ter à identidade do educando, à sua pessoa, a seu direito de ser. Creio poder afirmar, na altura destas considerações, que toda prática educativa demanda a existência de sujeitos, um que, ensinando, aprende, outro que, aprendendo, ensina, dai o seu cunho gnosiológico; a existência de objetos, conteúdos a serem ensinados e aprendidos; envolve o uso de métodos, de técnicas, de materiais; implica, em função de seu caráter diretivo, objetivo, sonhos, utopias, ideais. Daí a sua politicidade, qualidade que tem a prática educativa de ser politica, de não poder ser neutra (FREIRE, 2002, p. 27-28, grifo do autor).
\end{abstract}

O autor nos provoca a repensar o trabalho exercido pelo professor de Educação Especial no ambiente escolar e chama a atenção para a necessidade de uma postura política-pedagógica, que reflita na prática docente, na visão de professores especializados e no próprio papel na construção de uma sociedade inclusiva. A forma de luta contra o desrespeito dos poderes públicos pela educação cidadã começa exatamente 
pela retomada da identidade do professor de Educação Especial, não o restringindo a mero técnico-gestor do serviço de AEE. A discussão, acerca do processo de luta pelo direto à educação para estudantes com deficiências e dos desafios da prática pedagógica a serem vencidos na construção de um sistema educacional inclusivo, é um instrumento fundamental no processo de atuação política-pedagógica do professor de Educação Especial.

A preocupação com o viés técnico-gestor da atuação docente, fundamentado nas atribuições prevista na Resolução CNE/CEB n 4/2009, restringe o professor de Educação Especial a competência de realizar uma avaliação diagnostica com base no laudo emitido, elaborar um plano de AEE a partir do atendimento individual e dos aprendizados atribuídos às SRM, além de selecionar recursos de acessibilidade voltados para o processo de aprendizagem e comunicação, capazes de auxiliar também nas atividades de vida cotidiana (BRASIL, 2009). Tal concepção tende a reduzir a ação do professor do AEE ao ensino e aplicação de técnicas e recursos, eliminando a natureza pedagógica, social e política do trabalho docente.

Pacheco (2007) acrescenta que, sem desconsiderar as especificidades individuais dos estudantes, este professor deve propor aos professores de sala de aula comum novos métodos de ensino e avaliação, que podem auxiliar também os demais estudantes da escola. Entretanto, em muitas instituições de ensino, o diálogo entre professores que atuam no AEE e os demais professores e gestores da escola não se constrói de forma coletiva, considerando o estudante PAEE como sujeito de aprendizagem e responsabilidade de todos da escola, não apenas do professor de Educação Especial. A resistência à inclusão dos estudantes com deficiência na escola tem sido extensiva aos professores de Educação Especial, e muitas escolas os veem como profissionais privilegiados que, por trabalharem individualmente com esses estudantes, estão em melhores condições, como afirmam os professores:
[...] mas na sua sala tem um arzinho condicionado (Professor V, informação verbal).

[...] uma sala deste tamanhinho de nada (Professor C, informação verbal).

[...] então é aquilo que foi falado antes, é a falta de conhecimento, do que é o professor do AEE (Professor F, informação verbal).

[...] acha que é vida mansa tá aposentado, falta de conhecimento, não entenderam o que é a sala... (Professor $\mathrm{C}$, informação verbal).

[...] tem que ter coração, a não ser que você tenha sei lá... um pedaço de madeira, porque você sabe que eu tô trabalhando ali... com um aluno com baixa visão... e saber que o médico disse pra mãe: "- mãe procure uma escola de Braile, porque ele vai precisar, porque ele vai perder a visão!". Então e aí? Você vai ficar feliz com uma situação dessa? eu tô dizendo minha gente quanto mais mexe... vê se essa criança não tem a possibilidade de fazer um plano, de fazer alguma coisa... eu tô sofrendo com aquilo, não é fácil não... ai as professoras passam: "- eita, que tá com a vida boa!"... minha sala tava com a porta aberta e... "- eita que é só um aluno ali ó!" Vamos ajudar esse aluno, ele não está enxergando nada e ele não tem possibilidade de fazer Braile em Maceió, porque ele é um sozinho, a coitada da mãe não tem como trazer ele e o médico disse: "- é mãe ele vai precisar frequentar a escola ele tem que aprender Braile, porque ele vai ficar cego". Entendeu? então é muito fácil isso? (Professor J, informação verbal).

O desconhecimento sobre o trabalho exercido pelo professor de Educação Especial e a dinâmica de trabalho realizado no AEE ofertado na SRM constituem um dos motivos de desentendimento e isolamento destes profissionais na escola regular. O diálogo entre os professores revela que na escola eles se sentem marginalizados, e assim como a maioria dos estudantes com deficiência são excluidas do cotidiano da instituição.

Prioste (2011) revela em suas pesquisas que as dificuldades de comunicação e integração da equipe escolar são queixas recorrentes dos professores de Educação Especial. A falta de integração e o desconhecimento do trabalho realizado por estes profissionais e o realizado pelos professores da sala de aula comum dificultam os momentos de diálogo, discussão, trocas de experiências e planejamento entre estes profissionais. Dessa forma, torna-se inviável um trabalho educacional que fortaleça a transversalidade desta modalidade de ensino e, o AEE configura-se como um processo solitário 
ou de isolamento, contrastando com a natureza de uma escola que visa o fortalecimento de ambiente democrático e inclusivo, calcada sob a égide de um trabalho coletivo e participativo, como afirma o professor $\mathrm{C}$ :

[...] mas a gente encontra barreira... tem professor da educação física que eles não querem trabalhar com a criança com deficiência... (Professor C, informação verbal).

Este talvez seja o verdadeiro paradoxo vivenciado todos os dias por professores de Educação Especial nas escolas públicas alagoanas, excluídos do coletivo da escola, não convidados a participarem da construção, da implementação ou da atualização do PPP ou dos momentos de planejamento coletivo e com estudantes marcados no recreio ou na sala de aula, com o rótulo "estes são da Educação Especial" (Professor C, informação verbal). Professores isolados em ilhas de conhecimentos específicos e perdidos em salas exclusivas-excluídas, que dialogam apenas com os estudantes PAEE ou com seus pares nos cursos de formação que participam.

De acordo com Teixeira (2012) a fragmentação da SRM do ambiente escolar acontece devido a falhas no programa de SRM. Os gestores municipais ao assinar a adesão ao Programa se comprometem em garantir as condições mínimas necessárias à sua implantação (indicação das escolas, recrutamento de professores para atuar no AEE e espaço físico adequado), sem antes dialogar com a gestão das escolas. Em Maceió, algumas escolas que receberam o Kit do MEC não conseguiram implantar esse programa (MERCADO, 2016), seja porque os gestores escolares não concordavam com a proposta de inclusão total ou por não aceitarem disponibilizar espaços escolares para este fim, ainda que a escola fosse beneficiada pela dupla matrícula.

Divergência no horário de trabalho e sobrecarga de atividades estão também entre as principais razões para a manutenção do planejamento descontextualizado ou da realização de práticas de reforço escolar no interior das SRM. Ser professor nesse cenário tem sido um desafio que os professores que atuam no AEE, participantes deste estudo, vivenciam no dia a dia das escolas públicas de Alagoas.

\section{Relação formação e atuação do professor de AEE}

Com tantas atribuições e diferenciações elencadas para o professor que trabalha no AEE a partir da Resolução CNE/CEB n 4/2009, a formação continuada passa a ser foco de muitos programas nacionais e das secretarias. Uma das formas utilizadas para realizar esta ação é relatada pelo professor $L$ ao descrever os encontros com vários professores para dialogar sobre os estudantes à luz da perspectiva da educação inclusiva.

[...] orientar... orientar como passar também para os professores... como trabalhar com aquele aluno... orienta em tudo... no atendimento em tudo... pra que a gente possa também orientar os outros envolvidos (Professor L, informação verbal).

Os modelos de formação ofertados pelas Secretarias de Educação desconsideram as discussões politicas do papel desse professor no processo de inclusão escolar ou simplesmente não as contemplam, como alerta Michels (2011, p. 83): "Não encontramos, nesses documentos, uma preocupação explicita em relação ao papel do professor referente à lida com conhecimento. Esta parece ser uma função secundarizada, ou "antiga", dentre as tarefas docentes". A ausência de tais discussões remete tanto à perda da identidade profissional do professor de Educação Especial, quanto à definição da atuação deste profissional junto aos estudantes, pais e demais professores da escola, conforme relata Baptista (2013, p. 48-49):

Tenho presenciado reações curiosas de profissionais altamente qualificados diante de análises que mostram a precariedade de muitos contextos educacionais que se propõem como organizadores em nome da inclusão escolar [...]. O desafio, portanto, [...] está predominantemente associado à dimensão da formação (como formar esse novo profissional que ainda não existe?) e à requalificação (trata-se de uma tarefa para a qual devemos contar com profissionais que existem e que estão em campo, mas que devem construir capacidades que possivelmente ainda (hes são estranhas). 
É fundante pensarmos que, talvez, este novo modelo de professor traga um redimensionamento da concepção de politica de Educação Inclusiva, dos documentos legais e dos programas de formação oferecidos em âmbito nacional e local. Além do redimensionamento da organização e gestão das escolas, que abre espaços para a inclusão das SRM, não por imposição dos programas federais, mas por acreditar que a escola democrática e preocupada com a garantia do direito à educação é antes de tudo inclusiva.

De acordo com Prieto (2003), a formação proporcionada a maioria dos professores brasileiros é a alternativa de melhoria das práticas pedagógicas exercidas e do nivel de conhecimento destes profissionais, consequentemente, melhoria da qualidade de ensino dos estudantes atendidos na Educação Especial. O lugar da Educação Especial como fundamento, em muitos modelos de curso, está centrado no início do curso, com carga horária pequena, de natureza não-obrigatória, desarticulado com o cotidiano das escolas e sem proposição com o desenvolvimento de habilidades para resolução de problemas institucionais. Este movimento é representado na fala do professor A, ao relatar como aconteceu o processo de formação inicial no curso de Pedagogia.

[...] como professor de sala de aula nós não recebemos formação pra isso nos cursos de licenciatura, nem no curso de pedagogia, né... nossa carga horária das nossas disciplinas elas são pouquíssimas... e na minha época era assim você fazia educação especial se você quisesse, era optativa, não era uma coisa obrigatória... agora não ela faz parte da grade... ela tá lá... é uma disciplina obrigatória... então diante disso a gente tem assim um contexto bem diversificado... se a gente não tiver essa formação continua a gente se perde naquele contexto... (Professor A, informação verbal).

Na compreensão do processo histórico dos Cursos de Pedagogia, Garcia (2013) retoma os conflitos do processo histórico da formação de professores de Educação Especial no Brasil. Na década de 1970, os professores de Educação Especial eram formados em Curso de Pedagogia, a partir da oferta de habilitações em áreas especificas de deficiências. Com a aprovação da
Lei n 9.394/1996 reiterou-se a possibilidade de formação destes professores também em curso do magistério de nível médio. A aprovação da Resolução CNE/CP n¹/2006, ao instituir as diretrizes para o Curso de Pedagogia, passa a deliberar a extinção das habilitações e repassa o lócus de formação de professores de Educação Especial para os cursos de pós-graduação lato sensu (BRASIL, 2006).

Este movimento impulsionou a criação de vários cursos de especialização e aperfeiçoamento na área da Educação Especial, oferecidos tanto pelo setor privado, quanto por programas de formação do MEC em parceria com universidades públicas. O Programa de Apoio a Planos de Reestruturação e Expansão das Universidades Federais (REUNI) impulsiona a criação de licenciaturas nas universidades, entretanto a oferta de cursos de graduação em Educação Especial não apresentou uma expansão significativa, concentrando-se basicamente no eixo Sul-Sudeste.

A compreensão deste cenário revela que em Alagoas a formação inicial de professores da Educação Especial se dá basicamente por uma disciplina eletiva de fundamentos no curso de Pedagogia, ou nos cursos de especialização oferecidos pelas redes privada e pública. Para muitos professores, a oferta de cursos de aperfeiçoamento do governo federal ainda é a alternativa mais viável e contínua.

Na fala do professor $F$ também é destacada a importância de uma formação específica na área, ainda que esteja sendo disponibilizada apenas no modelo de formação continuada. Esta necessidade é justificada, exatamente, pela especificidade do atendimento às necessidades do grupo em questão, a correlação interdisciplinar com os saberes, competências e habilidades desenvolvidas nas salas comuns do ensino regular e com outros ambientes ou instituições voltadas para formação pessoal e social desses estudantes.

[...] ó deixa eu te perguntar assim: agora mesmo essa formação que a gente tá fazendo com a Joana... ela tava levando o profissional da área de determinada deficiência, e tá sendo muito bom... por exemplo essa semana [...] aquilo ali deixa ele perturbado, eu tava doida pra enfeitar a 
minha sala com cartazes e tal, e ele disse que eu teria de colocar os meus brinquedinhos, quando fosse a vez dele, para a sala de AEE, porque perturba ele e tal... ai quando foi essa semana que eu fui atender: - e aí como vai? essa sala tá muita bagunçada? quer saber vamos arrumar? (Professor F, informação verbal).

O professor $\mathrm{F}$ enfatiza que os momentos de formação continuada são configurados como espaços destinados a preparação dos professores, a partir da troca de informações e experiências entre o palestrante convidado e os professores que se identificarem com a situação relatada, e repensam seu ambiente e suas práticas. Davis et al. (2011), afirmam que há um grande esforço das secretarias de educação em atender às demandas dos profissionais, buscando realizar formações que levem em conta os anseios dos professores e sejam realizadas de forma contínua, evitando formações de caráter pontual e/ou de curta duração.

Entretanto, o próprio documento da PNEE-El/2008 esclarece que "para assegurar a intersetorialidade na implantação das políticas inclusivas a formação docente deve contemplar conhecimentos de gestão de sistemas educacional inclusivo" (BRASIL, 2008, p. 11), além do desenvolvimento de ações intersetoriais, conforme descrito pelo professor $\mathrm{A}$ :

[...] não porque todas tem mais embasamento teórico do que prático... só que eu não vou relatar aqui pra você assim... mas se você quiser saber sobre autista... mas eu passei o ano todinho... o ano passado... todas as formações que eu ia era autismo... autismo... autismo... minha gente e os outros...tão aonde... mas só teoria... se fui fazer um curso de autismo ... mas eu fui fazer em... mas eu fui fazer em Recife... que foi uma questão prática... uma questão minha... por conta própria... mas eu sinto está falta... (Professor A, informação verbal).

A proposta de desenvolver atividades voltadas ao enriquecimento curricular e ao ensino de linguagens e códigos específicos (BRASIL, 2008) tem orientado as agências formadoras para oferecerem, aos professores de Educação Especial, cursos ou ações de formação continuada voltados à aquisição de conhecimentos específicos dos diferentes tipos de deficiências, transtornos globais de desenvolvimento e altas habilidades/ superdotação. Tais cursos ou ações formativas pressupõem que o domínio desses saberes ou das sugestões de trabalho apresentados sejam suficientes para subsidiar as práticas pedagógicas desenvolvidas nas SRM.

O foco da política de SRM é a preocupação na formação de professores que atuarão com base nos saberes relacionados às deficiências, aos transtornos globais de desenvolvimento e às altas habilidades/superdotação, desenvolvendo habilidades que garantam o uso eficaz de recursos, de materiais de acessibilidade e pedagógicos voltados ao Braille, Libras, TA e CAA. Segundo Borowski (2010), este modelo de formação continuada enfatiza a aplicação de recursos práticos diferentes para cada especificidade. Mizukami (2002) destaca que este modelo de formação tende a privilegiar apenas aspectos médico-pedagógico e psicopedagógicos, desconsiderando as dimensões socioculturais e político-ideológicos da profissão docente.

No desvelar das falas dos professores, acrescenta-se uma critica na forma como estes saberes são "repassados" e na ausência de articulação com o dia a dia das SRM. Aspectos já denunciados por Garcia (2013), ao analisar um dos programas de formação utilizados pelo governo federal e multiplicado por muitas Secretarias de Educação, inclusive pela Secretaria Municipal de Educação de Maceió (BARROS, 2010). Estes programas tratam de temáticas voltadas as especificidades do público-alvo e do exercício cotidiano das SRM, fundado na organicidade, na superficialidade de conteúdos teóricos e na apresentação de sugestões de atividades. Não há espaço, nem lugar para investigação, reflexão, discussão e intervenção nos problemas e nas realidades vivenciadas por cada professor.

As falas dos professores $\mathrm{T}$ e $\mathrm{M}$ demonstram que não há mudanças nesse cenário de formações vivenciadas pelos professores.

[...] era só apresentação como ela falou ou eles colocavam outras coisas também... (Professor T, informação verbal).

[...] realmente está tendo muita formação... mas muita teoria... talvez para o pessoal que entrou 
agora... porque eu sou do pessoal mais antigos... a gente não tá mais sentindo tanta necessidade de tanta teoria a gente tá querendo mais a prática... e as meninas que entraram agora... tão chegando agora... realmente tão precisando dessa teoria, né? E eu concordo quando a gente coloca que não pode teoria e prática ser [...] eu vou mostrar um trabalho que eu tô realizando... tá mas mostre na prática... vá confeccione o material com a gente... diga com é que a gente vai trabalhar a partir daquele indicador daquela sua pesquisa... porque de repente a gente fica ali saturado... então é importante o autismo... é... não eu tô discordando que é... mas eu também acredito que deficiente intelectual tem outras problemáticas que a gente tá precisando... o deficiente visual... o au... o au... auditivo... (Professor $M$, informação verbal).

As falas demonstram o clamor por um modelo de formação continuada que ressignifique a relação teoria e prática, aproximando-se das inquietações e necessidades cotidianas dos professores de Educação Especial. Tal paradigma encontra-se fundamentado na concepção de reflexão-sobre-a-ação, conceito defendido por Schön (1995) na década de 1990.

É por intermédio da tríade reflexão-açãoreflexão que o professor analisa o conhecimento técnico e busca a solução de problemas, que se manifesta no saber fazer e no refletir sobre sua ação. "Neste momento o professor articula a situação problemática de forma as metas e a escola dos meios, com suas teorias e convicções pessoais, dentro de um contínuo" (SCHÖN, 1995. p. 17). O professor, nessa perspectiva, se aproxima do estudante e o envolve no processo de construção do conhecimento. A análise reflexiva deste processo permite a esse profissional, em um processo de formação continuada, transformar sua prática.

A angústia dessas professoras, com relação ao modelo de formação adotado, ganha força também nas ideias de Borges e Almeida (2008), ao defender que formar o professor vai além da simples prática de repassar informações e conceitos; é prepará-lo para outro modo de educação que altere sua relação com os conteúdos a serem trabalhados e as experiências e necessidades dos estudantes. Nesse contexto, o professor é agente fundamental do processo inclusivo e transformador de suas práticas.
Outra visão de formação é apresentada nos estudos de Glat e Pletsch (2012) sobre o modelo de formação fundado nos parâmetros de pesquisa-ação, que busca atender de imediato a demanda apontada pelos professores por meio do diálogo permanente com os formadores, ao agregar diferentes contribuições e ao elaborar de forma coletiva soluções para as dificuldades e desafios encontrados no exercício da prática pedagógica desenvolvida. É possivel que esse novo modelo de formação venha a responder as necessidades e desejos apresentados anteriormente pelos professores T e M.

Portanto, as falas apresentadas no grupo focal, ao descrever de forma reflexiva as práticas pedagógicas desenvolvidas por professores que atuam no AEE e o processo de formação ofertado pelas Secretarias de Educação, revelaram inquietações e desafios pertinentes para a implantação da inclusão escolar. O professor de Educação Especial é, muitas vezes, desvalorizado no interior da própria escola e o modelo formativo vigente tem como foco o AEE, materializado na SRM. São aspectos que consideram esse profissional apenas como um mero executor dos recursos pedagógicos e de acessibilidade, retirando da sua atuação e formação a natureza pedagógica da docência. Rediscutir o papel do professor de Educação Especial à luz de uma atuação politico-pedagógica é de extrema importância para o resgate da dignidade do estudante PAEE, e aponta a necessidade de revisão dos programas formativos e das normativas legais.

\section{Considerações finais}

Ao discutir sobre a visão dos professores de Educação Especial, a partir do trabalho desenvolvido nas SRM e das formações vivenciadas, desvelamos as angústias e certezas desses professores quanto à necessidade de formação voltada para o exercício da ação docente. Aspectos relacionados à constituição do processo identitário e de atuação nas SRM e na escola como um todo ainda se encontram nebulosos. Ao longo do texto, é apresentada uma linha tênue e tensa do espaço de atuação deste profissional: ora muito 
articulado ao espaço da SRM; ora perdido/isolado/excluido no espaço escolar.

Temos falas representativas de angústias e inquietações de professores que vivem a solidão da educação inclusiva. É perceptivel em muitas escolas que os estudantes atendidos nas SRM são considerados apenas estudantes público-alvo do AEE e não da escola, os professores dessa modalidade são excluidos dos momentos de planejamento participativo ou da participação na gestão escolar. A formação oferecida ocorre em ambiente exclusivo, extraescolar e apenas com a presença dos pares, que nesse momento deveriam ao menos ter a chance de dialogarem, trocarem experiências, refletirem em ações interventoras que busquem soluções para os desafios enfrentados.

Revisitando os desafios da formação à atuação do professor de Educação Especial nas SRM, concordamos com Jesus e Vieira (2011) ao defender que a formação inicial e a continuada devem fornecer elementos que fortaleçam os professores na promoção de diálogos fecundos entre teoria e prática, de forma que possam refletir sobre o vivido, o experienciado e os desafios surgidos. O processo de formação deve ser dinâmico, permanente e integrado no dia a dia dos professores e das escolas e não como uma ação desenvolvida pelas agências formadoras que estão muitas vezes à margem dos projetos profissionais e organizacionais de cada escola.

Os modelos de formação oferecidos pelas agências formadoras desvelam que existe uma ênfase em conteúdos e cursos preparados por especialistas, para aquisição ou aprimoramento de saberes essenciais ao AEE, distante das realidades enfrentadas no cotidiano das escolas públicas alagoanas. A preocupação com a ênfase na preparação de professores executores de recursos pedagógicos e de acessibilidade ainda estão muito presentes nas diretrizes das políticas educativas norteadoras dos programas de formação.

Corroboramos com paradigmas que defendem um modelo de formação no qual educação e diversidade dialogam, acreditando que o processo formativo é o espaço de valorização da relação teoria e prática, por meio da reflexão crítica da ação educativa, situação que ocasiona transformação de pensamento dos professores e das práticas desenvolvidas.

Não é possivel refletir acerca das formações oferecida a estes professores no exercício da sua função se não tivermos clareza da necessidade de revisitarmos os Cursos de Formação de Professores de caráter inicial, responsabilidade que complete às Instituições de Educação Superior (IES). Nestes cursos, os futuros professores devem conhecer as especificidades das pessoas com necessidades educacionais especiais, os referenciais teórico-práticos do ensino e aprendizagem da Educação Especial e do sistema regular de ensino, bem como os paradigmas sócio-políticos-pedagógicos que perpassam a ação docente.

\section{Referências}

BAPTISTA, C. R. Ação pedagógica e educação especial: para além do AEE. In: JESUS, D. M.; BAPTISTA, C. R.; CAIADO, K. M. Prática pedagógica na educação especial: multiplicidade do atendimento educacional especializado. Araraquara: Junqueira \& Marin, 2013. p. 21-61.

BARROS, J. L. A formação continuada de professores na perspectiva da educação inclusiva no municipio de Maceió, 2010. Dissertação (Mestrado em Educação) - Centro de Educação, Programa de Pós-Graduação em Educação, Universidade Federal de Alagoas, Maceió, AL, 2010.

BITENCOURT, T. V. DE; ARAÚJO, A. P. Inclusão escolar e ressignificação da formação docente: possibilidades e desafios a partir das contribuições de Gadamer. Educação Por Escrito, Porto Alegre, RS, v. 5, n. 1, p. 41-50, 26 jun. 2014

BORGES, D. C.; ALMEIDA, M. L. O grupo de formação continuada: múltiplos olhares sobre a questão da inclusão escolar. In: ALMEIDA, M. A.; MENDES, E. G. HAYASHI, M. C. Temas em Educação Inclusiva: múltiplos olhares. Araraquara/SP: Junqueira \& Marin, 2008. p. 95-103.

BOROWSKI, F. Fundamentos Teóricos do Curso de Aperfeiçoamento de Professores para o Atendimento Educacional Especializado (2007): novos referenciais? 2010. Dissertação (Mestrado em Educação) - Centro de Ciências da Educação, Programa de Pós-Graduação em Educação, Universidade Federal de Santa Catarina, Florianópolis, SC, 2010 
BRASIL. Lei nº 9.394, de 20 de dezembro de 1996. Estabelece as diretrizes e bases da educação nacional Diário Oficial [da] República Federativa do Brasil: seção 1, Brasilia, DF, ano 134, n. 248, p. 27839, 23 dez. 1996.

BRASIL. Resolução CNE/CP n ${ }^{1}$, de 15 de maio de 2006. Institui Diretrizes Curriculares Nacionais para - Curso de Graduação em Pedagogia, Licenciatura. Brasilia, DF: CNE/MEC 2006.

BRASIL. Ministério de Educação. Portaria Normativa $\mathbf{n}^{\circ}$ 13, de 24 de abril de 2007. Brasília, DF: Ministério da Educação, 24 abr. 2007. Assunto: Programa de Implantação de Salas de Recursos Multifuncionais

BRASIL. Política Nacional de Educação Especial na perspectiva da Educação Inclusiva. Brasília, DF: MEC/ SEESP, 2008

BRASIL. Resolução CNE/CEB $n^{\circ} \mathbf{4}$, de 2 de outubro de 2009. Institui Diretrizes Operacionais para o Atendimento Educacional Especializado na Educação Básica, modalidade Educação Especial. Brasilia, DF: CNE/ MEC, 2009

BRASIL. Decreto n 7.611, de 17 de novembro de 2011 Dispõe sobre a educação especial, o atendimento educacional especializado e dá outras providências. Diário Oficial [da] República Federativa do Brasil: Edição Extra, seção 1, Brasilia, DF, ano 148, n. 221-A, p. 5-6, 18 nov. 2011

DAVIS, C. L. et al. Formação continuada de professores em alguns estados e municípios do Brasil. Cadernos de Pesquisa, São Paulo/SP, v. 41, n. 144, set./dez, 2011.

FREIRE, P. Pedagogia da autonomia: saberes necessários à prática educativa. 24 ed. Rio de Janeiro: Paz e Terra, 2002.

GARCIA, R. M. Politica de educação especial na perspectiva inclusiva e a formação docente no Brasil. Revista Brasileira de Educação, Rio de Janeiro, RJ, v. 18, n. 52, p. 101-119, jan./mar 2013.

GATTI, B. A. Grupo Focal na Pesquisa em Ciências Sociais e Humanas. Brasília: Liber Livro 2005.

GLAT, R.; PLETSCH, M. Inclusão escolar de alunos com necessidades especiais. 2 ed. Rio de Janeiro: EdUERJ, 2012.

JESUS, D. M.; VIEIRA, A. B. Formação de profissionais da educação e inclusão escolar: conexões possiveis. In: MAGALHÃES, R. C. (org.). Educação Inclusiva: escolarização, politica e formação docente. Brasilia: Liber, 2011. p. 135-156.

MENDES, E. G.; MALHEIRO, C. A. L. Salas de recursos multifuncionais: é possivel um serviço "tamanho único" de atendimento educacional especializado? In: MIRANDA, T. G.; GALVÃO FILHO, T. A. (org.). O professor e a educação inclusiva: formação, práticas e lugares. Salvador: EDUFBA, 2012. p. 349-365.
MERCADO, E. L. Identidades do professor de educação especial no contexto de Maceió-Alagoas.2016. Tese (Doutorado em Educação) - Centro de Educação, Programa de Pós-Graduação em Educação, Universidade Federal de Alagoas, Maceió, 2016.

MIRANDA, T. G. As múltiplas dimensões da formação docente para uma escola inclusiva: uma reflexão a partir da perspectiva cultural. Revista Entreideias, Salvador, BA, v. 4, n. 1, p. 13-34, jan./jun. 2015.

MIZUKAMI, M. G. et al. Escola e aprendizagem da docência: processos de investigação e formação. São Paulo: EdUFSCar, 2002.

MICHELS, M. H. O que há de novo na formação de professores para a EducaçãoEspecial? Revista Educação Especial, Santa Maria, RS, v. 24, n. 40, p. 219-232, maio/ago. 2011.

PACHECO, J. et al. Caminhos para a inclusão: um guia para o aprimoramento da equipe escolar. Porto Alegre: Artmed, 2007.

PLETSCH, M. D. A formação de professores para a educação inclusiva: legislação, diretrizes políticas e resultados de pesquisa. Educar, Curitiba, PR, n. 33, p. 143-156, 2009.

PRIETTO, R. G. Formação de professores para o atendimento de alunos com necessidades educacionais especiais: diretrizes nacionais para a educação básica e a educação especial. In: SILVA, S.; VIZIM, M. Políticas públicas: educação, tecnologias e pessoas com deficiências. Campinas: Mercado de Letras; Associação de Leitura do Brasil, 2003. p. 125-152.

PRIOSTE, C. Educação inclusiva: de que se queixam os professores de escola pública? In: AMARAL, M.; SOUZA, $M$ (org.) Educação pública nas metrópoles brasileiras. Jundiaí: Paço; São Paulo: Edusp, 2011. p. 71-93.

SCHÖN, D. Educando o profissional reflexivo: um novo design para o ensino e a aprendizagem. Porto Alegre: Artmed, 1995

TEIXEIRA, L. Salas de recursos multifuncionais: uma proposta complementar. In: ENCONTRO NACIONAL DE DIDÁTICA E PRÁTICAS DE ENSINO, 14., 2012, Campinas. Anais [...]. Campinas, SP: Unicamp, 2012.

UNESCO. Declaração de Salamanca: sobre principios, práticas e políticas na área de necessidades educativas especiais. Brasilia, DF: UNESCO, 1994.

UNESCO. Declaração Mundial de Educação para todos e Plano de Ação para satisfazer as necessidades básicas de aprendizagem. Brasilia, DF: UNESCO, 1990.

UNICEF. Relatório Situação Mundial da Infância 2013: crianças com deficiência. Nova lorque, USA: UNICEF, 2013.

VAZ, K. O professor de educação especial na política de educação especial na perspectiva inclusiva. In: IX ANPED SUL - Seminário de Pesquisa em Educação da Região Sul, 9., 2012, Caxias do Sul. Anais [...]. Caxias do Sul, RS: UCS, 2012. p. 1-16. 


\section{Elisangela Leal de Oliveira Mercado}

Doutora em Educação pela Universidade Federal de Alagoas (UFAL), em Maceió, AL, Brasil; mestre em Letras e Linguistica pela Universidade Federal de Alagoas (UFAL), em Maceió, AL, Brasil; graduada em Pedagogia pela de Alagoas (UFAL), em Maceió, AL, Brasil; professora adjunto da Universidade Federal de Alagoas (UFAL), em Maceió, AL, Brasil.

\section{Neiza de Lourdes Frederico Fumes}

Doutora em Ciências do Desporto e Educação Física pela Universidade do Porto (UP - PORTUGAL), em Porto, Portugal; mestre em Ciência do Movimento Humano pela Universidade Federal de Santa (UFSM), em Santa Maria, RS, Brasil; graduada em Educação Física pela Universidade Estadual Paulista Júlio de Mesquita Filho (UNESP), em Rio Claro, SP, Brasil; professora titular da Universidade Federal de Alagoas (UFAL), em Maceió, AL, Brasil.

\section{Endereço para correspondência}

Elisangela Leal de Oliveira Mercado/ Neiza de Lourdes Frederico Fumes

Universidade Federal de Alagoas

Centro de Educação

Av. Lourival Melo Mota, $s / n$

Tabuleiro do Martins, 57072-900

Maceió, AL, Brasil

Os textos deste artigo foram revisados pela Poá Comunicação e submetidos para validação das autoras antes da publicação. 